\title{
A Community Health Assessment Curriculum to Develop Population Health Competencies
}

\author{
Jacob Prunuske, MD, MSPH | Patrick L. Remington, MD, MPH
}

Published: 2/8/2017 | DOI: 10.22454/PRiMER.2017.1.1

\section{Abstract}

Introduction: The Institute of Medicine, Association of American Medical Colleges, and Centers for Disease Control and Prevention recommend population health training for medical students. Medical schools struggle to teach and evaluate population health curricula. We developed, implemented, and evaluated a community health assessment exercise $(\mathrm{CHA})$ within a required clinical rotation to address this need.

Methods: Descriptive statistics and t-test comparison of means were used to analyze student scores on curricular assignments and responses to pretest and posttest items assessing student-rated skill and likelihood of conducting a CHA in practice, and in finding evidence to support public health programs and policies.

Results: Student-rated skill in conducting a CHA increased from $3.3 \pm 1.2$ on the pretest to $4.8 \pm 0.9$ on the posttest $(P<$ 0.01 ). Student-rated skill in finding evidence that supports public health programs and policies increased from $4.0 \pm 1.1$ to $5.1 \pm 0.9(P<0.01)$. There was no difference between pretest and posttest in the likelihood of participating in a CHA organized by others $(4.7 \pm 1.3$ vs $4.9 \pm 1.3, p=0.4)$, or in initiating a CHA as a practicing physician $(4.2 \pm 1.4$ vs $4.3 \pm 1.4, P$ $=0.8$. Asked if the CHA improved their educational experience, $56 \%$ of students agreed and $25 \%$ disagreed. Asked if the CHA improved their ability to provide patient care, $40 \%$ of students agreed and $37 \%$ disagreed.

Conclusions: The addition of a $\mathrm{CHA}$ to a clinical rotation is feasible and develops key medical student public health competencies.

\section{Introduction}

Healthy People 2020 identifies health indicators that must be addressed to improve the health of the United States population. ${ }^{1}$ The leading causes of death in the United States are associated with lifestyle-related conditions and influenced by community and environment. ${ }^{2}$ Responding to calls from the Institute of Medicine (IOM), Association of American Medical Colleges (AAMC) and Centers for Disease Control and Prevention (CDC) to strengthen population health training, ${ }^{3-5}$ we sought to integrate public health competencies into medical education. Many medical schools struggle to effectively evaluate community and systems aspects of health and health care and want methods to teach and evaluate learning. ${ }^{6}$ We developed, implemented, and evaluated a community health assessment exercise ( $\mathrm{CHA}$ ) within a required fourth-year community preceptorship.

\section{Methods}

The University of Wisconsin School of Medicine and Public Health Preceptorship was a required 6-week community medicine rotation for fourth-year medical students. In the 2010-2011 academic year, the preceptorship core clinical experiences were 
augmented by the addition of a required CHA. Students completed an anonymous four-item pretest rating statements on a 7-point Likert scale ( 0 = very low, 7 = very high). The items included statements regarding skills and likelihood of conducting a $\mathrm{CHA}$ and in finding evidence to support public health programs and policies.

Students conducted a guided CHA. Students were required to describe their preceptorship community, identify community members' perceptions of health problems, identify objective health information, describe leading health problems, and identify a single priority health issue in their preceptorship community. Students then identified an evidence-based intervention to address the priority health issue, completed a written report, and presented their work at the end-of-rotation workshop. Points were assigned to each CHA task and a rubric was used for grading. Students could earn up to 53 points via the rubric. The full CHA and grading rubric are available on the STFM Resource Library. ${ }^{7}$

Student performance on the CHA was graded and counted for one-quarter of the final course grade. After the CHA, students completed an anonymous posttest. The posttest contained the same items as the pretest and additional items regarding educational experiences.

Descriptive statistics and t-test comparison of means were used to analyze student scores and responses to pretest and posttest items. The Shapiro-Wilk test was used to assess normality of the range of student scores. Data were analyzed using STATA (Stata/IC 12.1 for Mac, Revision 20 Mar 2013. Copyright 1985-2011 StataCorp LP. College Station, TX). This project was approved by the University of Wisconsin Education Research IRB.

\section{Results}

One hundred forty-one students completed the $\mathrm{CHA}$. Student scores for the $\mathrm{CHA}$ exercise were normally distributed ( $P=0.02$ ) (Figure 1). The mean student score was $45.7 \pm 2.9$ points (range $37-52$ ). Student-rated skill in conducting a CHA increased from $3.3 \pm 1.2$ on the pretest to $4.8 \pm 0.9$ on the posttest $(P<0.01)$. Student-rated skill in finding evidence that supports public health programs and policies increased from $4.0 \pm 1.1$ to $5.1 \pm 0.9(P<0.01)$. There was no difference between pretest and posttest in the likelihood of participating in a CHA organized by others ( $4.7 \pm 1.3$ vs $4.9 \pm 1.3, p=0.4$ ), or in initiating a CHA as a practicing physician ( $4.2 \pm 1.4$ vs $4.3 \pm 1.4, P=0.8)$. Responses to the pre- and posttest items are shown in Figures $2 \mathrm{a}-2 \mathrm{~d}$. Asked if the CHA improved their educational experience, $56 \%$ of students agreed and $25 \%$ disagreed. Asked if the $\mathrm{CHA}$ improved their ability to provide patient care, $40 \%$ of students agreed and $37 \%$ disagreed.

\section{Conclusion}

The addition of a CHA to a clinical rotation improved students self-rated skill in conducting a $\mathrm{CHA}$ and in finding evidence that supports public health programs and policies without affecting their likelihood of initiating or participating in a $\mathrm{CHA}$ as a practicing physician. CHA are feasible in a preclinical training. ${ }^{8}$ Our findings show feasibility of implementing a $\mathrm{CHA}$ on a clinical rotation and that doing so helps develop student public health competencies.

Knowledge of community health issues should allow physicians to improve care and health outcomes through application of public health principles toward practice policies and decisions. ${ }^{9}$ However, our students reported mixed impacts on their ability to provide patient care. It may be that students who put greater effort into the CHA perceived greater benefit. We asked students to rate the statement "The community health assessment activity improved my ability to provide patient care on this rotation." Because the assignment took students away from patient care responsibilities, some students may have perceived this as negatively impacting their ability to provide patient care.

Despite improving confidence, this activity did not alter students' likelihood of saying they intend to participate in CHA as a physician. Students may perceive CHA to be the work of governmental public health or hospital-based systems rather than practicing physicians. Public health efforts can benefit from physician engagement and additional research should explore factors that motivate physicians to participate in $\mathrm{CHA}$.

On the individual CHA steps, students commonly neglected to address environmental determinants, consistent with the results of the 2013 AAMC Graduation Questionnaire, in which 34\% of students reported inadequate education in 
environmental health, ${ }^{10}$ and age or gender in the demographics of their community, suggesting a need to increase training in these areas.

Students were less likely to engage with non-patient community members, despite narrative feedback that reflected enjoyment of interaction with community members. This may relate to students' temporary placement and role within the community. Physicians living and working in the community may have greater opportunity to interact with community members in non-professional settings.

This study is limited by self-reported measures and a single academic year at one institution. We believe the self-reported measure are relevant, as confidence may affect future behavior, regardless of students' current perceptions of likelihood in engaging in a CHA as a future doctor. Future studies should qualitatively explore student perspectives regarding the value and impact of the CHA.

In conclusion, the addition of a CHA to a clinical rotation is feasible and develops key medical student public health competencies. Future research should explore strategies to foster development of attitudes, beliefs, and skills that will increase students' likelihood of community engagement as future physicians.

\section{Tables and Figures}

\section{Figure 1: Distribution of Student Scores on Community Health Assessment Exercise (53 pts possible)}




Figure 2a: Pre/Post Frequency of Response for Skill in Conducting a Community Health Assessment

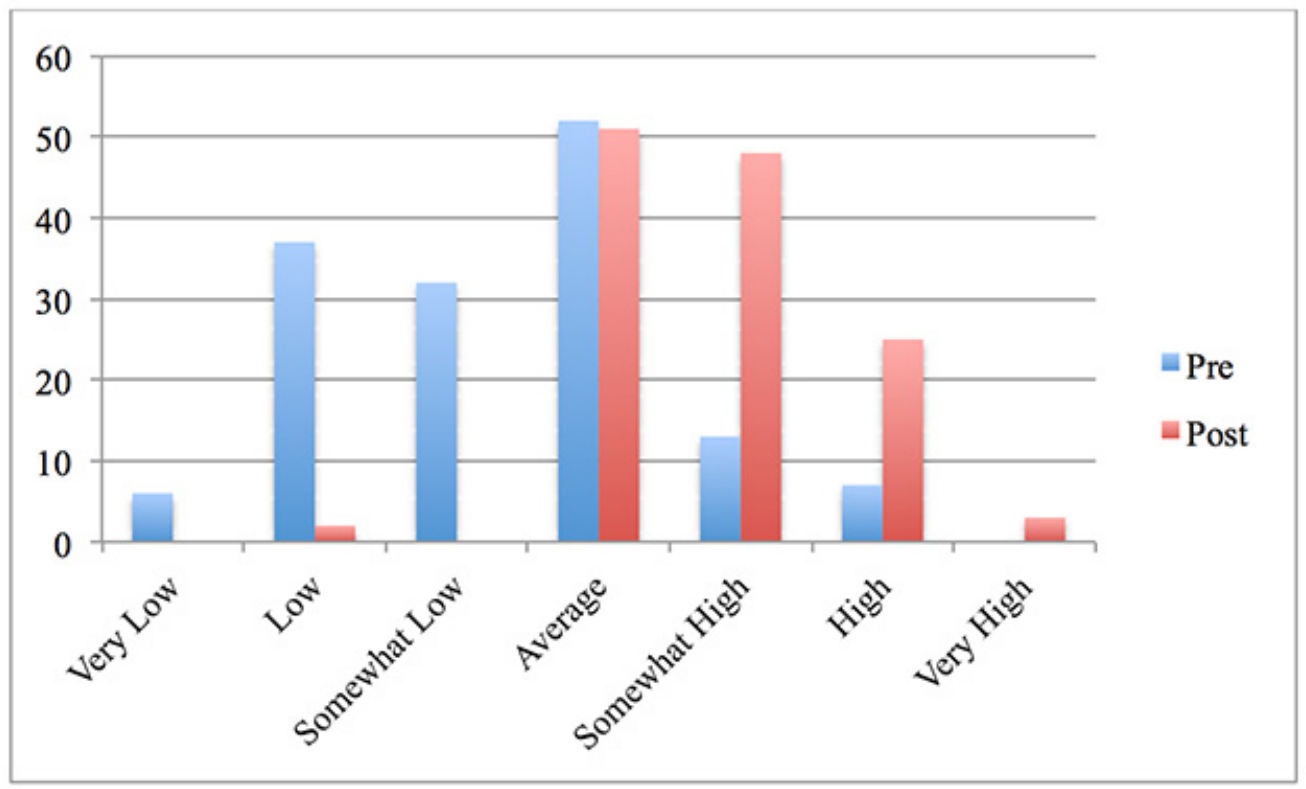

Figure 2b: Pre/Post Frequency of Response for Skill in Finding the Evidence That Supports Public Health Programs and Policies

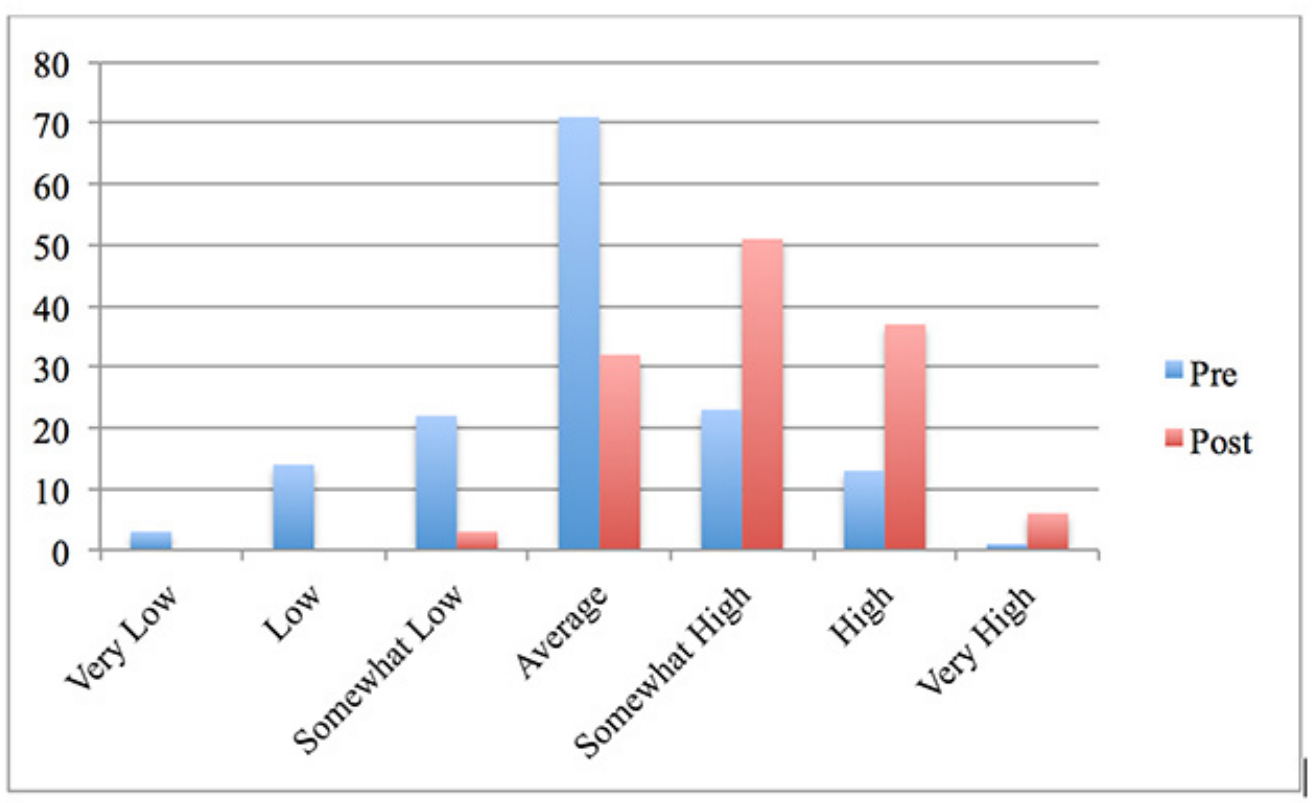


Figure 2c: Pre/Post Frequency of Response for Likelihood of Participating in a Community Health Assessment Organized By Others

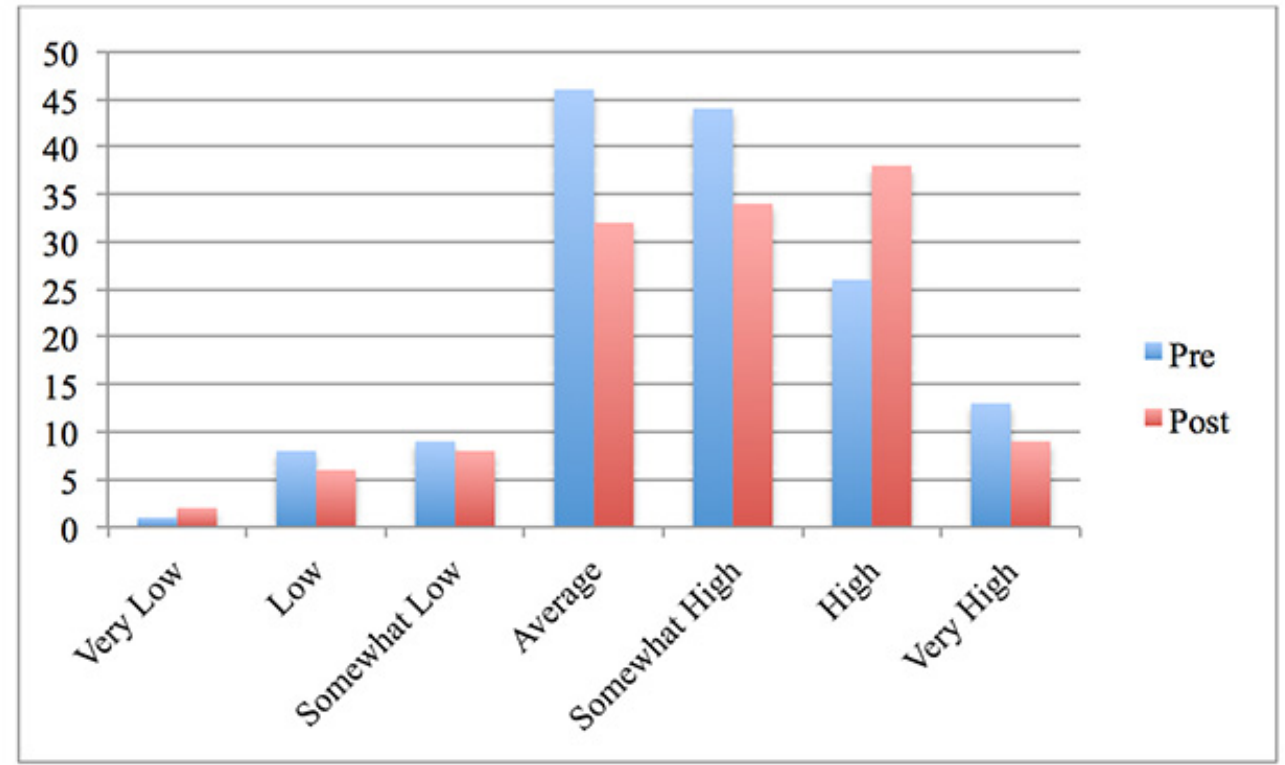

Figure 2d: Pre/Post Frequency of Response for Likelihood of Initiating a Community Health Assessment as a Practicing Physician

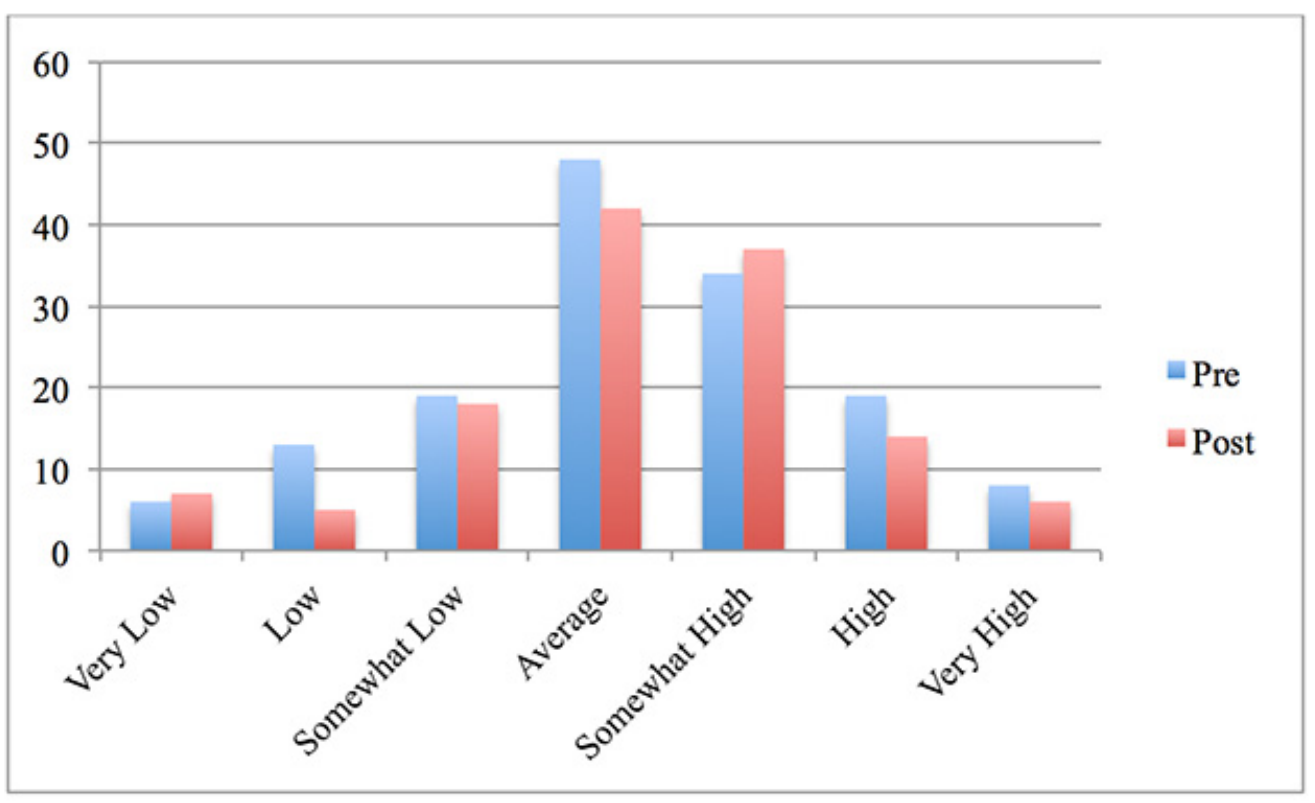

Acknowledgements

Preliminary results for this manuscript were presented at the Midwest Family Medicine conference in Itasca, Illinois, 


\section{Author Affiliations}

Jacob Prunuske, MD, MSPH - Medical College of Wisconsin - Central Wisconsin

Patrick L. Remington, MD, MPH - University of Wisconsin, School of Medicine and Public Health

\section{References}

1. Healthy People 2020. http://www.healthypeople.gov/2020/LHI/default.aspx.

2. National Center for Health Statistics http://www.cdc.gov/nchs/data/dvs/lead1900_98.pdf. Accessed December 2, 2010.

3. IOM. Who Will Keep the Public Healthy? Educating Public Health Professionals for the 21st Century. Washington, DC: National Academies Press; 2002.

4. Program NRM. Results and Data. 2016 Main Residency Match. Washington, DC: National Resident Matching Program; 2016.

5. Maeshiro R. Responding to the challenge: population health education for physicians. Acad Med 2008;83(4):319-320. doi:10.1097/ACM.0b013e318166ae9f.

6. Garr DR, Lackland DT, Wilson DB. Prevention education and evaluation in U.S. medical schools: a status report. Acad Med. 2000;75(7 Suppl):S14-21.doi:10.1097/00001888-200007001-00003.

7. Prunuske J, Remington P. Community Health Assessment Exercise. 2016. STFM Resource Library. https://resourcelibrary.stfm.org/viewdocument/community-health-assessmentexercis?CommunityKey=2751b51d-483f-45e2-81de-4faced0a290a\&tab=librarydocuments

8. Davison H, Capewell S, Macnaughton J, Murray S, Hanlon P, McEwen J. Community-oriented medical education in Glasgow: developing a community diagnosis exercise. Med

Educ 1999;33(1):55-62. doi:10.1046/j.1365-2923.1999.00266.x

9. Stone DH. Public health in the undergraduate medical curriculum--can we achieve integration? J Eval Clin Pract 2000;6(1):9-14. doi:10.1046/j.1365-2753.2000.00227.x

10. AAMC. GQ Medical School Graduation Questionnaire. 2013.

Copyright $@ 2017$ by the Society of Teachers of Family Medicine 